\title{
Pengaruh Proses Pengendalian Manajemen dan Gaya Kepemimpinan terhadap Kinerja Manajerial
}

\author{
Irma Suci Laswati* \\ Prodi Akuntansi, Fakultas Ekonomi dan Bisnis, Universitas Islam Bandung, \\ Indonesia. \\ *irmasucilaswati@yahoo.com
}

\begin{abstract}
This study aims to determine the effect of management control processes and leadership style on managerial performance. The object of research used in this study is the management control process, leadership style, and managerial performance. The subjects in this study were the managers of state-owned companies in the city of Bandung. The research method used is verification with aquantitative approach. This study uses primary data with purposive sampling method with a sample of 45 managers. Hypothesis testing in this study using multiple linear regression analysis. From the results of the tests carried out, the results showed that the management control process had aasignificant positive effect on managerial performance, while leadership style had a significant effect on managerial performance. Suggestions for further researchers are to add research samples or test other variables to find out what factors can improve managerial performances.
\end{abstract}

\section{Keywords: Management Control Process, Leadership Style, Managerial Performance}

Abstrak. Penelitian ini bertujuan untuk mengetahui pengaruh proses pengendalian manajemen dan gaya kepemimpinan terhadap kinerja manajerial. Objek penelitian yang digunakan dalam penelitian ini adalah proses pengendalian manajemen, gaya kepemimpinan, dan kinerja manajerial. Subjek dalam penelitian ini adalah manajer perusahaan BUMN di Kota Bandung. Metode penelitian yang digunakan adalah verifikatif dengan pendekatan kuantitatif. Penelitian ini menggunakan data primer dengan metode purposive sampling dengan sampel sebanyak 45 manajer. Pengujian hipotesis dalam penelitian ini menggunakan analisis regresi linier berganda. Dari hasil pengujian yang dilakukan, hasil penelitian menunjukkan bahwa proses pengendalian manajemen berpengaruh signifikan positif terhadap kinerja manajerial, sedangkan gaya kepemimpinan berpengaruh signifikan terhadap kinerja manajerial. Saran bagi peneliti selanjutnya yaitu dapat menambah sampel penelitian atau menguji variabel lain untuk mengetahui faktor apa saja yang dapat meningkatkan kinerja manajerial

Kata Kunci: Proses Pengendalian Manajemen, Gaya Kepemimpinan, Kinerja Manajerial 


\section{A. Pendahuluan}

Saat ini perusahaan-perusahaan tumbuh berkembang dan bersaing semakin ketat, ditambah dengan kemajuan teknologi serta tantangan dan peluang dalam bisnis. Perusahaan diharapkan dapat bertahan dalam menghadapi persaingan agar dapat lebih maju dan berkembang di Indonesia ini. Manajemen memegang peranan yang penting di dalam perusahaan agar perusahaan dapat berhasil mencapai tujuannya. Dalam rangka mencapai tujuannya perusahaan membentuk pusat-pusat pertanggungjawaban.

Manajemen di dalam suatu perusahaan memiliki hierarki tertentu. Menurut John Suprihanto (2014) manajemen merupakan suatu perencanaan, memimpin, pengorganisasian, dan pengendalian sumber daya manusia lainnya dalam mencapai tujuan organisasi. Manajemen juga merupakan suatu fungsi yang berhubungan melalui orang lainu ntuk memperoleh suatu hasil tertentu. Seperti yang dikemukakan oleh Millet (1954) bahwa manajemen adalah melakukan sebuah kinerja dari orang-orang yang telah teroganisir dengan berbagai kelompok untuk memperoleh suatu tujuan.

Manajemen pun tentu harus mempunyai kinerja yang baik karena akan mempengaruhi lingkungan internal perusahaannya. Seperti yang dikemukakan oleh Mangkunegara (2003) kinerja merupakan kerja seseorang secara kualitas juga secara kuantitas yang diperoleh oleh seorang karyawan dalam menjalankan tugasnya. Namun menurut Umar (2019) kinerja manajerial merupakan ukuran sebagaimana manajer bekerja secara efektif dan efesien manajer dalam mencapai tujuan organisasi.

Fenomena yang terjadi saat ini adalah telah terjadinya kinerja manajerial yang buruk. Bank BRI bahwa Standar Operasional Prosedur (SOP) yang seharusnya dilaksanakan menjadi tidak dilaksanakan. Sehingga saat itu, terjadi pesengkongkolan yang tidak disadari oleh nasabah, dan terjadi penyimpangan yang dilakukan oleh manajerial Bank BRI yaitu melakukan kredit fiktif (Wilman, 2020).

Indikasi adanya pengaruh proses pengendalian manajemen terhadap kinerja manajerial ini telah dibuktikan pada penelitian sebelumnya yang dilakukan oleh (Sari \& Saragih, 2016) menyatakan bahwa proses pengendalian manajemen secara parsial berpengaruh positif terhadap kinerja manajerial karena dengan adanya pengendalian manajemen yang kuat akan memperkuat kinerja manajer disetiap bidang dan bagiannya. Sejalan dengan penelitian (Tendean et al., 2018) bahwa proses pengendalian manajemen mempunyai pengaruh signifikan terhadap kinerja manajerial. Karena penerapan proses pengendalian manajemen semakin baik, maka kinerja manajerial akan meningkat. Namun berbanding terbalik dengan hasil penelitian (Gani \& Jermias, 2012) menunjukkan bahwa proses pengendalian manajemen memiliki korelasi negatif yang signifikan terhadap kinerja.

Selain proses pengendalian manajemen, gaya kepemimpinan juga berpengaruh terhadap kinerja manajerial. Seperti penelitian yang telah dilakukan oleh (Sugianto Yusuf et al., 2018) menunjukkan bahwa gaya kepemimpinan terdapat pengaruh yang signifikan secara simultan terhadap kinerja manajerial. Karena variasi gaya kepemimpinan dapat menjelaskan variasi dengan meningkatnya kinerja manajerial. Sejalan dengan penelitian (Rohman et al., 2019) menjelaskan bahwa gaya kepemimpinan mempengaruhi kinerja manajerial. Penelitian selanjutnya diperkuat oleh (Hakim, 2018) menunjukkan bahwa gaya kepemimpinan memiliki pengaruh yang siginifikan terhadap kinerja manajerial karena model teori tujuan gaya kepemimpinan terdiri dari kepemimpinan yang direktif, partisipatif, suportif, dan kepemimpinan yang berorientasi pada performa seseorang dan mampu mempengaruhi, mendorong, dan mengerahkan anggota unit kerja untuk memperbaiki kinerja manajerial. Namun berbading terbalik dengan hasil penelitian (Ridwan \& Hamelinda, 2017) bahwa gaya kepemimpinan tidak berpengaruh signifikan terhadap kinerja manajerial.

Berdasarkan latar belakang masalah tersebut, maka dapat diambil identifikasi masalah yaitu:

1. Seberapa besar pengaruh proses pengendalian manajemen terhadap kinerja manajerial.

2. Seberapa besar pengaruh gaya kepemimpinan terhadap kinerja manajerial. 
Berdasarkan uraian identifikasi masalah, maka tujuan penelitian ini yaitu:

1. Untuk mampu menjelaskan besarnya pengaruh proses pengendalian manajemen terhadap kinerja manajerial.

2. Untuk mampu menjelaskan besarnya pengaruh gaya kepemimpinan terhadap kinerja manajerial.

\section{B. Metodologi}

\section{Proses Pengendalian Manajemen}

Proses pengendalian manajemen yaitu manajer memengaruhi anggota dalam suatu organisasi untuk mengimplementasikan program dan rencana organisasi (Anthony \& Govindarajan, 2012). Proses pengendalian manajemen juga merupakan alat bagi para manajer, yang digunakan dalam interaksi atau komunikasi diantara mereka dalam suatu organisasi (John Suprihanto, 2014). Menurut (Anthony \& Govindarajan, 20212) bahwa: dalam proses pengendalian manajemen, meliputi empat tahap. Empat tahap ini diantaranya adalah:

1. Perencanaan strategi

2. Penyusunan anggaran

3. Pelaksanaan

4. Evaluasi kinerja

\section{Gaya Kepemimpinan}

Gaya kepemimpinan adalah kompetensi seseorang untuk memengaruhi, memotivasi, menyesuaikan dan dapat membuat orang lain mampu dalam memberi kontribusi demi kelancaran efektivitas dan keberhasilan organisasi (Robbins \& Coulter, 2010). Selain itu, menurut (Tjiptono, 2006) bahwa: "Gaya kepemimpinan merupakan kombinasi dari karakteristik, kemampuan dan perilaku yang dilakukan seorang pemimpin untuk berinteraksi dengan karyawannya". Definisi serupa, dinyatakan oleh (Rivai et al., 2014) gaya kepemimpinan adalah suatu perilaku dan cara strategi seorang pemimpin yang selalu diterapkan dalam organisasi dalam rangka mencapai sasaran dan tujuan organisasi.

Ada 4 macam gaya kepemimpinan, empat gaya kepemimpinan (Robbins \& Coulter, 2010) yaitu:

1. Gaya kepemimpinan kharismatik

2. Gaya kepemimpinan transaksional

3. Gaya kepemimpinan transformasional

4. Gaya kepemimpinan visioner

\section{Kinerja Manajerial}

Kinerja Manajerial adalah performa yang dihasilkan oleh manajer dengan mengeluarkan bakat dan kemampuan, serta usaha orang lain dengan berbeda kelompok di dalam daerah wewenangnya (Mulyadi, 2009). Menurut (Mahoney, dkk., 1963) bahwa: "Kinerja manajerial sebagai kinerja manajer dalam kegiatan-kegiatan manajerial yang meliputi perencanaan, investigasi, pengkoordinasian, evaluasi, pengawasan, pengaturan staff, negosiasi, dan perwakilan atau representasi”.

Kinerja manajerial dapat diukur dan dilihat dari pelaksanaan delapan dimensi kinerja personal yaitu:

1. Planning

2. Investigating

3. Coordinating

4. Evaluation

5. Monitoring

6. Staffing

7. Negotiating

8. Representating

Metode penelitian yang digunakan dalam penelitian ini adalah metode penelitian verifikatif dengan pendekatan kuantitatif. Metode verifikatif dengan pendekatan kuantitatif 
dimaksudkan untuk menjelaskan masing-masing variabel dan hubungan antar variabel melalui pengujian hipotesis dengan cara mengolah data menggunakan statistik.

\section{Pembahasan dan Diskusi}

\section{Hasil Regresi Linier Berganda}

Hasil analisis regresi berganda untuk mengkaji pengujian hipotesis dalam penelitian ini. Di bawah hasil analisis regresi berganda menggunakan aplikasi SPSS:

Tabel 1. Hasil Regresi Linear Berganda



a. Dependent Variable: KM

Sumber: Hasil olah data SPSS 2021 berikut:

Persamaan regresi linier berganda yang didapatkan dari tabel diatas yaitu sebagai

$\mathrm{KM}=3,433+0,278 \mathrm{PPM}+0,671 \mathrm{GK}+\mathrm{e}$

1. Nilai konstanta konstanta $(\alpha)$ sebesar 3,433 artinya jika nilai variabel proses pengendalian manajemen (X1) dan gaya kepemimpinan (X2) bernilai konstan maka variabel kinerja manajerial (Y) bernilai sebesar konstanta yaitu 3,433.

2. Nilai b1 sebesar 0,278 artinya, jika variabel proses pengendalian manajemen (X1) meningkat satu unit sedangkan variabel gaya kepemimpinan (X2) konstan maka variabel kinerja manajerial (Y) meningkat sebesar 0,278.

3. Nilai b2 sebesar 0,671 artinya jika variabel gaya kepemimpinan (X2) meningkat satu unit sedangkan variabel proses pengendalian manajemen $(\mathrm{X} 1)$ konstan maka variabel kinerja manajerial (Y) meningkat sebesar 0,671.

\section{Uji Simultan (Uji F)}

Hasil uji simultan (uji F) diperoleh hasil pada tabel dibawah ini:

Tabel 2. Hasil Uji Simultan (Uji F)

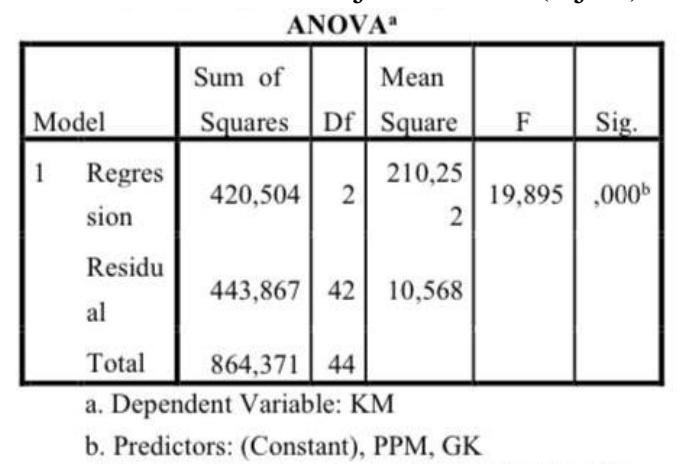

Sumber: Hasil Pengolahan SPSS versi 23, 2021

Berdasarkan hasil pengujian di atas, diperoleh nilai signifikan $\mathrm{F}$ sebesar $0,000<$ 0,05. Maka dapat disimpulkan Ha diterima (Ho ditolak) artinya bahwa proses pengendalian manajemen dan gaya kepemimpinan secara simultan berpengaruh terhadap kinerja 
manajerial.

\section{Uji Parsial (Uji t)}

Hasil uji parsial (uji t) diperoleh hasil pada tabel di bawah ini:

Tabel 3. Hasil Uji Parsial (Uji t)

\begin{tabular}{|l|c|c|c|c|}
\multicolumn{1}{|c}{ Coefficients } \\
& B & $\begin{array}{c}\text { Std. } \\
\text { Error }\end{array}$ & t & Sig. \\
\hline 1 (Constant) & 3,433 & 3,727 &, 921 &, 362 \\
& & & & \\
PPM &, 278 &, 075 & 3,706 &, 001 \\
GK &, 671 &, 222 & 3,021 &, 004 \\
\hline
\end{tabular}

a. Dependent Variabel: KM

Sumber: Hasil Pengolahan SPSS, 2021

Berdasarkan tabel 3 hasil pengujian di atas, nilai signifikan $t$ dari proses pengendalian manajemen sebesar 0,001 <0,05. Dapat disimpulkan, bahwa H1 diterima (Ho ditolak). Artinya proses pengendalian manajemen berpengaruh signifikan terhadap kinerja manajerial. Nilai dari uji parsial (uji t) untuk gaya kepemimpinan sebesar 0,004 < 0,05. Maka dapat disimpulkan bahwa $\mathrm{H} 2$ diterima (Ho ditolak). Artinya gaya kepemimpinan berpengaruh signifikan terhadap kinerja manajerial.

\section{Uji Koefisien Determinasi (Rsquare)}

Uji koefisien determinasi ini bertujuan untuk mengukur seberapa besar kontribusi proses pengendalian manajemen dan gaya kepemimpinan terhadap kinerja manajerial. Hasil analisis koefisien determinasi simultan (Rsquare) diperoleh hasil pada tabel berikut:

Tabel 4. Hasil Analisis Koefisien Determinasi Simultan (Rsquare)

\begin{tabular}{|l|c|r|r|c|}
\hline $\begin{array}{l}\text { M } \\
\text { od } \\
\text { el }\end{array}$ & R & $\begin{array}{c}\text { R Squ } \\
\text { are }\end{array}$ & $\begin{array}{r}\text { Adjusted } \\
\text { R Squa } \\
\text { re }\end{array}$ & $\begin{array}{c}\text { Std. Error } \\
\text { of the Est } \\
\text { imate }\end{array}$ \\
\hline 1 & $\begin{array}{r}697 \\
\mathrm{a}\end{array}$ &, 486 &, 462 & 3,25089 \\
\hline
\end{tabular}
a. Predictors: (Constant), PPM, GK
b. Dependent Variable: KM

Sumber: Hasil Pengolahan SPSS versi 23, 2021

Berdasarkan tabel 4 hasil di atas, nilai koefisien determinasi secara simultan (Rsquare) sebesar 0,486 atau dalam persentase yaitu $48,6 \%$. Hal ini menunjukkan bahwa kinerja manajerial mampu dipengaruhi oleh proses pengendalian manajemen dan gaya kepemimpinan dengan total kontribusi 48,6\%, dan sisanya 51,4\%.

Koefisien determinasi parsial (Rsquare) diperoleh pada tabel di bawah ini:

Tabel 5. Hasil Analisis Koefisien Determinasi Parsial (Rsquare)

\section{Coefficients}

\begin{tabular}{|l|c|c|c|}
\hline \multicolumn{1}{|c|}{ Model } & Sig. & Beta & $\begin{array}{c}\text { Zero } \\
\text { Order }\end{array}$ \\
\hline 1(Constant) &, 362 & & \\
PPM &, 001 &, 454 &, 612 \\
GK &, 004 &, 370 &, 564 \\
\hline
\end{tabular}

a. Dependent Variabel: KM 
Hasil perhitungan determinasi parsial (Rsquare), yaitu sebagai berikut:

$$
\begin{aligned}
\text { Kd }(\mathbf{P P M}) & =0,454 \times 0,612 \times 100 \% \\
& =27,78 \% \\
\mathbf{K d}(\mathbf{G K}) & =0,370 \times 0,564 \times 100 \% \\
= & 20,87 \%
\end{aligned}
$$

Berdasarkan dari hasil perhitungan tersebut, diperoleh nilai koefisien determinasi secara parsial (Rsquare) untuk variabel proses pengendalian manajemen memiliki pengaruh terhadap kinerja manajerial sebesar 27,78\%. Dan variabel gaya kepemimpinan memiliki pengaruh terhadap kinerja manajerial sebesar $20,87 \%$.

\section{Pengaruh Proses Pengendalian Manajemen Terhadap Kinerja Manajerial}

Berdasarkan hasil uji parsial (uji t) yang dimana nilai signifikan diperoleh yaitu 0,001 artinya lebih kecil dari tingkat alpha $(\alpha)$ yaitu 0,05 . Dan disimpulkan rumusan hipotesis dalam penelitian ini $\mathrm{H} 1$ diterima (Ho ditolak). Hal ini menunjukkan bahwa variabel Proses Pengendalian Manajemen (X1) berpengaruh secara positif dan siginifikan terhadap Kinerja Manajerial (Y).

Hasil nilai koefesien dari variabel Proses Pengendalian Manajemen (X1) sebesar 0,278 yang artinya, jika nilai proses pengendalian manajemen mengalami peningkatan, maka diprediksikan tingkat kinerja manajerial di 6 BUMN di Kota Bandung akan meningkat sebesar 0,278. Dalam perhitungan ini, menunjukkan besarnya pengaruh variabel Proses Pengendalian Manajemen terhadap Kinerja Manajerial sebesar 27,78\%.

Hasil tersebut sejalan dengan penelitian sebelumnya oleh (Sari \& Saragih, 2016) menunjukkan bahwa proses pengendalian manajemen berpengaruh positif terhadap kinerja manajerial karena dengan adanya pengendalian manajemen yang kuat akan memperkuat kinerja manajer setiap bidang dan bagiannya. Penelitian- penelitian selanjutnya diperkuat oleh (Tendean et al., 2018) proses pengendalian manajemen memiliki pengaruh signifikan terhadap kinerja manajerial karena baiknya penerapan proses pengendalian manajemen maka kinerja manajerial akan meningkat. Sejalan dengan penelitian sebelumnya oleh (Yustien, 2011) menjelaskan bahwa proses pengendalian manajemen berpengaruh positif terhadap kinerja manajerial.

\section{Pengaruh Gaya Kepemimpinan Terhadap Kinerja Manajerial}

Berdasarkan hasil uji parsial (uji t) yang dimana nilai signifikan yaitu 0,004 artinya lebih kecil dari tingkat alpha $(\alpha)$ yaitu 0,05 . Disimpulkan rumusan hipotesis dalam penelitian ini H2 diterima (Hoditolak).

Hal ini menunjukkan bahwa variabel Gaya Kepemimpinan (X2) berpengaruh secara positif dan siginifikan terhadap Kinerja Manajerial (Y).

Hasil nilai koefesien dari variabel Gaya Kepemimpinan (X2) sebesar 0,671 yang artinya jika nilai gaya kepemimpinan memperoleh peningkatan, maka diestimasikan tingkat kinerja manajerial di 6 BUMN di Kota Bandung akan meningkat sebesar 0,671. Dalam perhitungan uji koefisien determinasi parsial, menunjukkan bahwa besarnya pengaruh variabel Gaya Kepemimpinan terhadap Kinerja Manajerial sebesar 20,87\%.

Hasil tersebut sejalan dengan penelitian sebelumnya oleh (Sugianto Yusuf et al., 2018) menjelaskan bahwa gaya kepemimpinan terdapat pengaruh yang signifikan secara simultan terhadap kinerja manajerial. Penelitian-penelitian selanjutnya diperkuat oleh (Rohman et al., 2019) bahwa gaya kepemimpinan mempengaruhi kinerja manajerial. Sejalan ,dengan penelitian sebelumnya oleh (Hakim, 2018) menjelaskan bahwa gaya kepemimpinan memiliki pengaruh positif yang siginifikan terhadap kinerja manajerial karena model teori tujuan gaya kepemimpinan berorientasi pada prestasi mampu mempengaruhi, mendorong, dan mengerahkan anggota unit kerja untuk memperbaiki kinerja maajerial. 


\section{Kesimpulan}

Berdasarkan hasil penelitian yang telah dilaksanakan, maka penulis memperoleh kesimpulan berikut:

1. Proses pengendalian manajemen berpengaruh terhadap kinerja manajerial. Artinya manajemen menerapkan proses pengendalian manajemen dengan baik maka kinerja manajerial yang dihasilkan akan menjadi lebih baik pula.

2. Gaya kepemimpinan berpengaruh positif secara signifikan terhadap kinerja manajerial. Artinya semakin pemimpin menerapkan gaya kepemimpinannya dengan baik maka kinerja manajerial yang akan dihasilkan akan menjadi lebih baik pula.

\section{Daftar Pustaka}

[1] Adiputra, I. M. P., Gani, L., Rossieta, H., \& Hermawan, A. A. (2019). Pengaruh Misfit Ketidak pastian Bisnis yang Dipersepsikan dengan Levers of Control Terhadap Kinerja

[2] Asari, A. R. (2018). Perancangan Sistem Informasi Akuntansi Pembelian Pada PT Khomsah Khalifah Dengan Menggunakan Software PHP dan MySQL @ Is The Best: Accounting Information Systems and Information Technology Business Enterprise, 3(1), 249-261.

[3] Fajriati, D. I. (n.d.). FOUR SKILLS THAT EVERY MILLENNIALS MANAGER NEEDS EMPAT KETERAMPILAN YANG DIBUTUHKAN SETIAP MANAJER MILENIAL.

[4] Gani, L., \& Jermias, J. (2012). The Effects of Strategy-Management Control System Misfits on Firm Performance. Accounting Perspectives, 11(3), 165-196.

[5] Ghafur, U. J., \& Gapui, G. (2020). KABUPATEN PIDIE JAYA untuk menarik, mengembangkan, dan mempertahankan tenaga kerja yang efektif. penting untuk meningkatkan produktivitas kerja di lingkungan organisasinya. 1(November), 31-39.

[6] Hakim, A. (2018). Pengaruh Sistem Pengendalian Manajemen dan Gaya Kepemimpinan terhadap Kinerja Karyawan pada PT. Inti Bumi Perkasa. JASa (Jurnal Akuntansi, Audit Dan Sistem Informasi Akuntansi), 2(4), 40-53.

[7] Ikhtiyarini, P. F., \& Machmuddah, Z. (2019). Sistem Akuntansi Manajemen Memediasi Gaya Kepemimpinan dan Desentralisasi Terhadap Kinerja Manajerial. Perspektif Akuntansi, 2(1), 89-108.

[8] Lestari, S. D. (2012). PERANAN AKUNTANSI PERTANGGUNGJAWABAN SEBAGAI ALAT PENGENDALIAN BIAYA PEMASARAN (Studi kasus Pada PT. BIKASOGA). Universitas Widyatama.

[9] Mangkunegara, A. A. A. P. (2003). Manajemen Sumber Daya Manusia Perusahaan. In Remaja Rosdakarya.

[10] Martina, S., \& Syarifuddin, D. (2014). Pengaruh Pelatihan Dan Pengembangan Terhadap Prestasi Kerja Karyawan dfolokasiwisata Baturraden. Jurnal Pariwisata, I(1), 28-34. https://ejournal.bsi.ac.id/ejurnal/index.php/jp/ article/download/186/161

[11] Mulyadi. (2009). Kinerja Manajerial. Journal of Chemical Information and Modeling, 53(9), 1689-1699.

[12] Naibaho, S. M. (2019). Pengaruh Sistem Pengendalian Manajemen Terhadap Kinerja Manajerial pada PT. Sriwijaya Air (Garuda Indonesia Group) Medan. Universitas Medan Area.

[13] Oh, I. S., \& Berry, C. M. (2009). The Five Factor Model of Personality and Managerial Performance: Validity Gains Through the Use of 360 Degree Performance Rating. Journal of Applied Psychology. 